\title{
Management of small elevated pigmented choroidal lesions
}

\author{
DEVRON H. CHAR AND MICHAEL J. HOGAN \\ From the Department of Ophthalmology, University of California School of Medicine, San Francisco, \\ California 94143
}

SUMMARY The diagnosis of small choroidal melanomas may be difficult, and the natural history of these small tumours is poorly understood. We followed up 20 patients with the diagnosis of small choroidal melanomas for from 2 to 20 years. In 11 of these patients the melanoma was observed to grow. Nine of these patients have undergone enucleation. Eight of the eyes contained spindle B melanomas and one contained a melanoma of mixed cell type. None of the 20 patients has developed detectable metastatic disease. From this series and others reported it appears that close serial examinations without therapeutic intervention is safe in patients with small melanomas until growth is observed, and that there is little evidence to suggest that photocoagulation or radiotherapy is of greater benefit in those patients than close serial examination.

Controversy exists as to the correct management of small choroidal melanomas (Vogel, 1972; WesterfeldBrandon and Zeeman, 1957; Stallard, 1968). The detection and clinical differentiation of pigmented choroidal lesions may present diagnostic difficulties (Ferry, 1964; Reese and Howard, 1967). Making the correct diagnosis is even more difficult in those patients with small choroidal masses and good visual acuities whom the clinician elects to follow closely without therapeutic intervention.

While there have been many clinical and pathologic studies of the natural history of choroidal melanomas most are not germane to the analysis of risk factors in patients with small tumours. Some of these studies were done before indirect ophthalmoscopy was in routine use (Morgan, 1973; Papolczy, 1937); some were done on relatively small numbers of patients (Jensen, 1963; Macrae, 1953); and some were done on specimens submitted by physicians with varying degrees of clinical acumen (Wilder and Paul, 1951; Paul et al., 1962).

With the increased use of the indirect ophthalmoscopy and ancillary diagnostic tests our ability to diagnose smaller tumours has increased, but our

Supported in part by the Cancer Research Co-ordinating Committee, University of California, Berkeley, Ca., Grant no. 75 SF11; Fight for Sight, Inc., New York. New York; and USPHS Grant no. EY01759 from the National Eye Institute, National Institutes of Health.

Address for reprints: Dr D. H. Char, University of California Schoo of Medicine, Room S-322, San Francisco, California 94143, USA. understanding of the behaviour pattern of these smaller choroidal melanomas is still poorly delineated (Zimmerman, 1967; Shields and McDonald, 1974).

When a clinician observes a small, pigmented, choroidal mass he is faced with both a diagnostic and therapeutic dilemma. (1) is the lesion a choroidal melanoma? And (2) is it best treated by enucleation, photocoagulation, radiation, or observation alone? We have had the opportunity clinically to observe 20 patients with the diagnosis of small choroidal melanomas who have been followed up without therapeutic intervention for from two to 20 years. We think that the behaviour of their lesions may shed some light on the natural history and management of small pigmented choroidal mass lesions. The clinical course of these patients suggests that small asymptomatic melanomas can be safely followed without therapeutic intervention until definite growth is observed.

\section{Methods}

Twenty Caucasian patients with pigmented choroidal masses were seen in consultation. Most of the lesions were observed in visually asymptomatic patients on routine ophthalmological examinations. Sixteen of the 20 patients had initial visual acuities of 20/40 or better (Table 1). Thirteen patients were male and seven patients were female. All subjects had serial examination with direct and indirect ophthalmoscopy, fundus drawings, and Goldmann 
Table 1 Patients with small choroidal melanomas

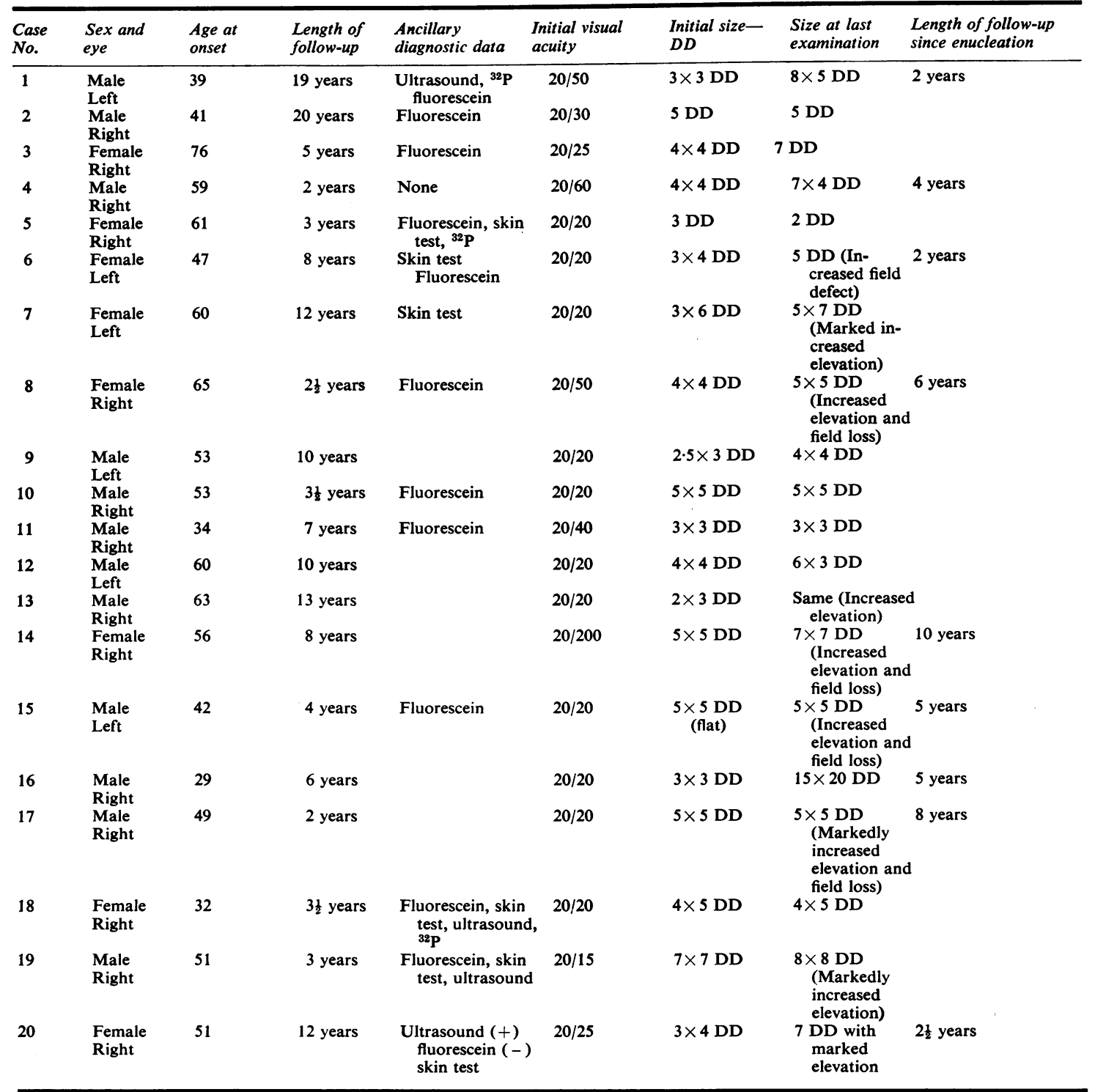

perimetry. Most patients had serial photographs taken, and some had ancillary diagnostic tests, including radioactive phosphorous uptake (3), ultrasound (4), fluorescein angiography (12), and a melanoma antigen skin test (6) (Table 1). None of these patients presented with a clinically apparent retinal detachment. Because of the patients' relatively good visual acuity, the small size of their lesions, and an intact Bruch's membrane, it was elected to follow them up after the possible malignant nature of their lesions was explained to them and all the therapeutic modalities were discussed. Patients were seen in follow-up at the University of California, San Francisco. In those cases where patients have left our geographical area, they and their current physicians have supplied follow-up information.

\section{Results}

All patients have been observed without therapeutic intervention for a period between two and 20 years (mean $7 \cdot 8$ years). On their initial examination the 
Table 2 Pathological data

\begin{tabular}{|c|c|c|c|c|c|c|c|c|c|}
\hline $\begin{array}{l}\text { Case } \\
\text { No. }\end{array}$ & $\begin{array}{l}\text { Cell } \\
\text { type }\end{array}$ & Pigment & $\begin{array}{l}\text { Break in Bruch's } \\
\text { membrane }\end{array}$ & $\begin{array}{l}\text { Retinal } \\
\text { detachment }\end{array}$ & Vascularity & $\begin{array}{l}\text { Intra-scleral } \\
\text { invasion }\end{array}$ & Necrosis & $\begin{array}{l}\text { Invasion to } \\
\text { outer sclera }\end{array}$ & $\begin{array}{l}\text { Intra- } \\
\text { tumour }\end{array}$ \\
\hline 1 & Mixed-B & Light & $(+)$ & $(+)$ & Moderate & + & - & + & 0 \\
\hline 4 & B & Light & $(-)$ & $(+)$ & Rare & - & - & - & - \\
\hline 6 & B & Moderate & $(-)$ & - & Rare & - & - & - & - \\
\hline 8 & B & Light-moderate & + & + & Frequent & + & + & - & $\div$ \\
\hline 14 & B & Light & + & + & Moderate & + & - & - & - \\
\hline 15 & B & $\begin{array}{c}\text { Moderate } \\
\text { heavy }\end{array}$ & - & + & $\begin{array}{l}\text { Moderate } \\
\text { frequent }\end{array}$ & - & - & - & - \\
\hline 16 & B* & & & & & & & & \\
\hline 17 & $\mathbf{B}$ & Light & - & + & Rare & - & - & - & - \\
\hline 20 & B & Heavy & + & + & Frequent & - & - & - & - \\
\hline
\end{tabular}

*Pathology done at another institution, sections not available.

average size of the pigmented choroidal mass was $4 \times 4 \mathrm{DD}$ with 1 to $2 \mathrm{~mm}$ of elevation. All patients had large absolute field defects the same size or larger than their lesion.

During the period of observation 11 patients were noted to have an increase in the size of their choroidal mass or visual field defect. Two of these patients (cases 7 and 19) have refused any treatment despite the development of much larger tumours with the clinical appearance of collar button lesions. Two other patients (cases 15 and 17) had minimal attempts at photocoagulation prior to enucleation. A total of nine patients in this series have had enculations.

Patients who underwent enucleation were followed up for an average of $7 \cdot 1$ years prior to surgery (range 2 to 19 years) and for a mean of 4.9 years (range 2 to 10 years) after enucleation. To date no patient has developed metastatic disease. On histological examination (Table 2) 8 of 9 eyes were shown to contain spindle B melanomas, and one eye (case 1) had a mixed cell tumour. Only in the latter case were tumour cells noted at the outside edge of the sclera. In only one patient was intratumour necrosis and haemorrhage noted (case 8). Exudative retinal detachments were observed in eight eyes, and a break in Bruch's membrane was noted in four.

Nine patients were still being observed without therapeutic intervention. In six the pigmented choroidal masses appear to have remained stationary or to have shown relatively little visual field or fundoscopic change (mean follow-up $8 \cdot 1$ years, range 3.5 to 13 years). Three patients have had clinical courses suggestive of a spontaneous regression (cases 2, 5, 10), with a diminution of the size of their choroidal lesions and field defects, and with a change in the surrounding retinal pigment epithelium. None of these nine patients has developed any sign of metastatic disease on clinical or laboratory evaluations.

Ancillary diagnostic tests were done in 13 patients. Three have had radioactive phosphorous uptake tests. Case 1, which later underwent enucleation, had a positive test with over $100 \%$ uptake. Cases 5 and 18 had results between 20 and $90 \%$ uptake and are still being followed up. Four patients have had A and B scan ultrasonography. In three of these cases the results were consistent with the diagnosis of choroidal melanoma, and this was confirmed histologically. In case 18 significant elevation was noted without choroidal excavation, and the patient is still being followed up.

Immunological tests were done in six patients. All six patients had positive reactions with a soluble melanoma skin test antigen. To date the specificity and sensitivity of this test has been greater than $90 \%$ (Char et al., 1974). Four of these patients have had the diagnosis of melanoma confirmed on pathological examination, one patient has refused enucleation despite a growing tumour, and another is being followed up. Twelve patients had fluorescein angiography. In five patients who were later enucleated three fluorescein angiograms were positive, two were equivocally positive, and one was negative. Of the seven patients who are still being followed up without therapeutic intervention two had characteristically positive angiograms and the other five had equivocal studies.

\section{Discussion}

Small pigmented choroidal lesions present the clinician with a diagnostic and therapeutic dilemma. Small choroidal melanomas, which most ocular oncologists define as less than $6 \mathrm{DD}$ in diameter and 1 to $2 \mathrm{~mm}$ in elevation, can be difficult to diagnose. The presence of an absolute scotoma as large as the lesion has been one criterion which has been quite helpful in differentiating naevi from choroidal melanomas (Flindall and Drance, 1969; Naumann et al., 1966; Naumann, 1970). While fluorescein angiography can be diagnostically useful when a characteristically positive pattern is observed, we and others have noted that it can often be falsely negative, especially in small melanomas (Pettit et al., 
1970; Hogeweg et al., 1976). We have found that ultrasonography is an excellent diagnostic tool in the workup of patients with large melanomas. However, our experience with it in small melanomas is still too limited to ascertain its specificity and sensitivity. In our institution and in others some benign lesions have had some of the characteristic ultrasound findings of a melanoma (J. Shields, personal communication), and we have observed patients with a false positive ultrasound diagnosis of melanoma who on histological examination had a benign lesion.

The radioactive phosphorous uptake test is a useful aid in the diagnostic workup of patients with choroidal masses. However, as with the above tests, its sensitivity and specificity in small choroidal lesions are unclear. Patients with small melanomas may have negative ${ }^{32} \mathrm{P}$ tests and benign lesions may give false positive results (Hogeweg et al., 1976; Cox, 1975). In patients whom we elect to follow up without therapeutic intervention we do not use the radioactive phosphorous test because of its established and theoretical risks. Ocular complications associated with the ${ }^{32} \mathrm{P}$ test include central retinal artery occlusion and intraocular haemorrhage (Burton, in press). At our institution we have observed these complications in less than $10 \%$ of ${ }^{32} \mathrm{P}$ studies done, but in patients who have good visual acuity whom we are planning to follow-up conservatively we feel this risk is unjustified. Further, we are concerned with the potential risks associated with this test. In some choroidal melanomas studied pathologically after ${ }^{32} \mathrm{P}$ testing the mechanical trauma of the ${ }^{32} \mathrm{P}$ probe appeared to increase the local dissemination of the tumour (unpublished observations). The dosage of ${ }^{32} \mathrm{P}$ given for diagnostic purposes (generally 500 to $750 \mu \mathrm{Ci}$ ) is near the range of therapeutic ${ }^{32} \mathrm{P}$ dosage $(2000$ to $7000 \mu \mathrm{Ci})$, and we have observed a number of patients who have had two and in one case three ${ }^{32} \mathrm{P}$ tests. The therapeutic use of ${ }^{32} \mathrm{P}$ has had significant morbidity associated with it (Modan and Lilienfeld, 1965; Lawrence et al., 1969), and we do not feel it is justifiable to use this test unless we plan to enucleate an eye if a positive result is obtained.

In nine of the patients in this series histological confirmation of the diagnosis of small choroidal melanoma was made. In the 11 other patients (two of who have experienced marked tumour growth but have refused therapy) we think that our diagnosis of small choroidal melanoma is correct. All patients had pigmented choroidal lesions which had at least 1 to $2 \mathrm{~mm}$ of elevation, and had absolute visual field defects greater than the size of their lesions. These findings and the results of the ancillary tests support our diagnosis. However, as mentioned previously, some simulating lesions cannot be ruled out (Shields and Font, 1972; Howard and Forrest, 1967). To date, the incidence of pathologically documented false positive diagnoses of choroidal melanoma is less than $2 \%$ at our institution (unpublished observation). The incidence of false negative diagnosis is difficult to ascertain. We are unaware of any patient we have clinically examined and recommended for further observation developing a metastatic melanoma.

In a pathological study by Davidorf and Lang (1974) it was noted that less than $30 \%$ of the patients with small choroidal melanomas had died by the end of 10 years. Two other clinical studies also suggest a much better prognosis for the small choroidal melanoma than has generally been assumed. Curtin and Cavender (1974) reported on 14 patients with small melanomas who are being initially followed up without therapeutic intervention. Of this group of patients, followed up on the average for more than six years, 13 are reported to be alive and without metastatic disease. Rubinstein and Myska (1974) followed up 18 patients for 3 to 14 years and treated 13 of them with either photocoagulation, radiation, or enucleation. After that length of follow-up it was noted that all 18 were clinically alive and well. In our study none of the patients had developed metastatic disease. These results suggest that the morbidity for patients having small choroidal melanomas is under $25 \%$ at five years. It also would appear that patients with small choroidal tumours may be followed up for relatively long periods of time until growth is documented without morbidity. Our results agree with the observation by Flocks et al. (1955), Zimmerman (1967), and Shields and McDonald (1974) that small choroidal melanomas are predominantly spindle cell in type.

In numbers sufficient for evaluation the modalities of radiotherapy and photocoagulation have been used as an alternative to enculeation in patients with small choroidal melanomas. In a group of 100 patients treated with a ${ }^{60} \mathrm{Co}$ plaques Stallard (1966) noted that 69 were successfully treated with radiotherapy. Six patients died of metastatic disease, and in 25 cases the possibility of therapeutic failure or uncertainty about the progression of the tumour dictated enucleation. Using a slightly different method of irradiation, Lommatzsch (1974) irradiated 62 patients with ${ }^{106} \mathrm{Ru} /{ }^{106} \mathrm{Rh}$ beta applicators between 1964 and 1971 . Of these patients $74 \%$ were considered to have undergone successful radiation; however, $26 \%$ had to have enucleation because of tumour growth or sequelae from the radiation. Some investigators have noted that radiotherapy to eye tumours has a significant incidence of morbidity 
(MacFaul and Bedford, 1970). Meyer-Schwickerath and Vogel (1974) have treated 54 patients, most of whom had small choroidal melanomas, with photocoagulation, and followed them up for over 10 years. In this group $46 \%$ were thought to be successfully treated and $27 \%$ died with metastatic disease. Similar results with photocoagulation have been noted by Francois (1974).

Two important conclusions can be drawn from the data presented. First, small choroidal melanomas are generally of a more benign histological character and have an excellent five-year prognosis. Secondly, to date there is little evidence to suggest that in patients with small choroidal melanomas treatment with either photocoagulation or radiotherapy is of any benefit over close serial follow-up without therapeutic intervention. Such treatment may in fact be deleterious. It would also appear that patients with small choroidal melanomas that have not shown growth can be safely followed up for relatively long periods of time without increasing the risk of morbidity or mortality.

When patients have asymptomatic small pigmented choroidal lesions diagnosed as melanomas we inform them that he or she has a possible malignant tumour and explain the various therapeutic options. If the patient elects it, we believe that frequent serial examination without therapeutic intervention is a reasonable course of management in these cases. In such cases noninvasive diagnostic tests, especially ultrasonography, may prove to be very useful. We have not found fluorescein angiography very helpful in patients with small lesions, and we feel that in patients who are going to be followed up without the possibility of surgical intervention the ${ }^{32} \mathrm{P}$ test is contraindicated. In those patients whose tumour shows growth on serial examination further diagnostic studies, including ${ }^{32} \mathrm{P}$ tests, are done and enucleation is usually recommended. In patients who present to our institution with large choroidal melanomas, with poor visual acuity, and a secondary detachment, enucleation is routinely performed after thorough ocular and metastatic diagnostic examinations. If patients refuse enucleation, or have a melanoma in their only functional eye (one-eyed patients or those who are amblyopic in the non-involved eye) we believe that therapeutic modalities such as photocoagulation, radiotherapy, and possibly total eye wall resection present reasonable alternative modes of therapy (Peyman, 1974).

We wish to thank Dr Ernest Goodner and other physicians who kindly referred the patients observed in this study, and Mrs Sadie Trauner for secretarial assistance.

\section{References}

Burton, T. C. (In press). Transactions of the American Academy of Ophthalmology and Otolaryngology.

Char, D. H., Hollinshead, A., Cogan, D. G., Ballintine, E. J., Hogan, M. J., and Herberman, R. B. (1974). New England Journal of Medicine, 291, 274.

Cox, M. S., Jr. (1975). Transactions of the American Academy of Ophthalmology and Otolaryngology, 79, 307.

Curtin, V. T., and Cavender, J. C. (1974). Modern Problems in Ophthalmology, 12, 523.

Davidorf, F. H., and Lang, J. R. (1974). American Journal of Ophthalmology, 78, 783.

Ferry, A. P. (1964). Archives of Ophthalmology, 72, 463.

Flindall, R. J., and Drance, S. M. (1969). Archives of Ophthalmology, 81, 41.

Flocks, M., Gerende, J. H., and Zimmerman, L. E. (1955). Transactions of the American Academy of Ophthalmology and Otolaryngology, 59, 740.

Francois, J. (1974). Modern Problems in Ophthalmology, 12 550.

Hogeweg, M., Bas, P. J. M., Greve, E. L., and DeHaan, A. B. (1976). Documenta Ophthalmologica, 40, 301.

Howard, C. M., and Forrest, A. W. (1967). Archives of Ophthalmology, 77, 61.

Jensen, O. A. (1963). Acta Ophthalmologica, Suppl. 75, 1.

Lawrence, J. H., Winchell, H. S., and Donald, W. G. (1969). Annals of Internal Medicine, 70, 763.

Lommatzsch, P. (1974). Survey of Ophthalmology, 19, 85.

MacFaul, P. A., and Bedford, M. A. (1970). British Journal of Ophthalmology, 54, 237.

Macrae, A. (1953). Transactions of the Ophthalmological Society of the United Kingdom, 73, 3.

Meyer-Schwickerath, G., and Vogel, M. H. (1974). Modern Problems in Ophthalmology, 12, 544.

Modan, B., and Lilienfeld, A. M. (1965). Medicine, 44, 305.

Morgan, G. (1973). Transactions of the Ophthalmological Society of the United Kingdom, 93, 71.

Naumann, G., Zimmerman, L. E., and Yanoff, N. (1966). American Journal of Ophthalmology, 62, 914.

Naumann, G. (1970). Fortschritte der Augenheilkunde, 23, 187.

Papolczy, F. Z. (1937). Klinische Monatsblätter für Augenheilkunde, 99, 518.

Paul, E. V., Parnell, B. L., and Fraker, M. (1962). International Ophthalmology Clinics, 2, 387.

Pettit, T. H., Barton, A., Foos, R. Y., and Christenson, R. E. (1970). Archives of Ophthalmology, 83, 27.

Peyman, G. A., Axelrod, H. A., and Graham, R. O. (1974). Archives of Ophthalmology, 92, 219.

Reese, A. B., and Howard, G. M. (1967). American Journal of Ophthalmology, 64, 1021.

Rubenstein, K., and Myska, V. (1974). Modern Problems in Ophthalmology, 12, 517.

Shields, J. A., and Font, R. L. (1972). Archhives of Ophthalmology, 87, 396.

Shields, J. A., and McDonald, P. R. (1974). Archives of Ophthalmology, 91, 259.

Stallard, H. B. (1966). British Journal of Ophthalmology, 59, 147.

Stallard, H. B. (1968). Modern Problems of Ophthalmology, 7, 16.

Vogel, N. H. (1972). American Journal of Ophthalmology, 74, 1.

Westerfeld-Brandon, E. R., and Zeeman, W. P. C. (1957). Ophthalmologica, 134, 20.

Wilder, H. C., and Paul, E. V. (1951). Military Surgery, $109,370$.

Zimmerman, L. E. (1967). Archives of Ophthalmology, 78, 166. 